\title{
Creativity and bipolar disorder: Touched by fire or burning with questions?
}

\author{
Sheri L. Johnsonn ${ }^{a}{ }^{\star}$, Greg Murray ${ }^{b}$, Barbara Fredrickson ${ }^{c}$, Eric A. Youngstrom ${ }^{c}$, Stephen \\ Hinshaw $^{\mathrm{a}}$, Julie Malbrancq Bass ${ }^{\mathrm{a}}$, Thilo Deckersbach ${ }^{\mathrm{d}}$, Jonathan Schooler ${ }^{\mathrm{e}}$, and Ihsan \\ Salloum ${ }^{\dagger}$ \\ aUniversity of California Berkeley, USA \\ bSwinburne University of Technology, Melbourne, Australia \\ cUniversity of North Carolina Chapel Hill, USA \\ 'Massachusetts General Hospital, USA \\ eUniversity of California Santa Barbara, USA \\ fUniversity of Miami Department of Psychiatry and Human Behavior, USA
}

\begin{abstract}
Substantial literature has linked bipolar disorder with creative accomplishment. Much of the thinking in this area has been inspired by biographical accounts of poets, musicians, and other highly accomplished groups, which frequently document signs of bipolar disorder in these samples. A smaller literature has examined quantitative measures of creativity among people with bipolar disorder or at risk for the disorder. In this paper, we provide a critical review of such evidence. We then consider putative mechanisms related to the link of bipolar disorder with creativity, by drawing on literature outside of bipolar disorder on personality, motivational, and affective predictors of creativity. Because so little research has directly evaluated whether these factors could help explain the elevations of creativity in bipolar disorder, we conclude with an agenda for future research on the theoretically and clinically compelling topic of creativity in bipolar disorder.
\end{abstract}

\section{Keywords}

Creativity; Bipolar disorder; Mania

\section{Introduction}

The apparent association between creativity and bipolar disorder has attracted academic and public interest for centuries. Lists of eminent artists potentially warranting the bipolar diagnosis are frequently cited (Goodwin \& Jamison, 2007; Rothenberg, 2001). As described by Kay Redfield Jamison (1993), biographical data suggests that mania may have affected Hemingway, Faulkner, Fitzgerald, Dickens, O'Neill, Woolf, Handel, Ives, Rachmaninoff, Tchaikovsky, Mingus, Charlie "Yardbird" Parker, Lord Byron, Coleridge, Dickenson, Plath,

\footnotetext{
All authors are members of the scientific board for the Sean Costello Memorial Fund for Bipolar Research, and we thank the organization for inspiring us to focus on this topic.

(c) 2011 Elsevier Ltd. All rights reserved.

"Corresponding author at: Psychology, 3210 Tolman Hall, University of California, Berkeley, CA 94720, USA. Tel.: +1 415347 6755. SLJohnson@ berkeley.edu (S.L. Johnson).
} 
Keats, Gauguin, O'Keefe, Munch, Pollock and Rothko, among others. The widespread belief that mania is a source of creative power is vividly exemplified by the worldwide release of a perfume named "Mania." Indeed, no other serious mental illness appears to have captured the public imagination as deeply. Of course, popular beliefs are not always supported by scientific findings. The aim of this paper is to consider the research base so far on bipolar disorder and creativity, and to provide an agenda for future research on bipolar disorder.

We believe that research on creativity in bipolar disorder may be particularly important for several reasons. First, evidence that bipolar disorder confers advantages for creative accomplishments would seem to be extremely helpful in improving public conceptualizations of disorder. Beyond influencing public attitudes, research demonstrates that a focus on strengths can enhance therapeutic outcomes (Berk, Berk, \& Castle, 2004), and this therapeutic task is supported by scientific research into adaptive qualities of the disorder (Wood \& Tarrier, 2010).

Before delving into the research on creativity and bipolar disorder, we provide background by considering definitions of bipolar disorder and creativity, as well as a few issues to consider in interpreting research in this area. We then review the evidence for direct links between bipolar disorder and various measures of creativity. Given broadly supportive evidence, we next focus on mechanisms that could help explain this link. We conclude with a set of recommendations for future research.

\section{Definitions and methodological issues}

It is important to consider how definitions of bipolar disorder may influence the profile of findings with respect to creativity. Similarly, we discuss the dominant approaches to the measurement of creativity.

\subsection{Definitions of bipolar disorder}

The optimal description of bipolar disorder phenomena is a matter of ongoing debate, with a variety of spectrum and dimensional conceptualizations receiving growing attention. Researchers have used diagnostic and dimensional approaches to mania in studies of creativity, so these constructs are briefly reviewed here.

The DSM-IV-TR defines several forms of bipolar disorder based on manic symptoms of varying severity and duration. Key symptoms include happiness and irritability, decreased need for sleep, racing thoughts, excessive confidence, increased energy, psychomotor agitation, and willingness to engage in reward-oriented behaviors without consideration of potential negative consequences (American Psychiatric Association, 2000). Bipolar I disorder is defined by at least one lifetime manic episode, whereas bipolar II disorder is defined by less severe hypomanic episodes along with depressive episodes. Cyclothymic disorder is defined by a chronic tendency toward recurrent high and low mood states that do not meet threshold for formal manic or depressive episodes. Cyclothymia has also been conceptualized as an affective "temperament," a biologically based individual difference that may be a diathesis for the development of fully syndromal mood disorders (Akiskal, Akiskal, Haykal, Manning, \& Connor, 2005). Cyclothymic and bipolar II disorders have been labeled as bipolar "spectrum" disorders, to capture that these disorders share many features with bipolar I even though affected persons have not (yet) met full criteria for a manic episode (Akiskal \& Pinto, 1999; Berk \& Dodd, 2005). Both cyclothymic disorder and bipolar II are characterized by hypomanic symptoms and pronounced mood instability (Ghaemi et al., 2008); both also show some evidence of familial aggregation with mania (Berk \& Dodd, 2005). In addition, many people with cyclothymic disorder or bipolar II eventually develop a full manic or mixed episode, thus "progressing" to a bipolar I diagnosis 
over time (Angst, Felder, Frey, \& Stassen, 1978; Angst et al., 2003). Rates of bipolar II disorder are also highly elevated among the families of those with bipolar I disorder (Simpson et al., 1993). Among those with cyclothymic disorder, about $42 \%$ will develop bipolar II and $10 \%$ will develop bipolar I disorder within a 4.5-year period, and among those with bipolar II disorder, about $10 \%$ will develop bipolar I disorder within a 4.5 -year period. Similarly, data in youths suggest that the rate may be higher than $30 \%$ conversion to bipolar I or II over a two to four year period (Birmaher et al., 2009; Kahana, 2006). Despite evidence for conversion, a large proportion of people stably demonstrate milder forms of the disorder (Merikangas \& Pato, 2009). Bipolar II disorder is also distinguished from bipolar I disorder by a greater propensity toward depressive episodes (Judd et al., 2005).

In addition to studies of people diagnosed with bipolar disorder, we will review how creativity relates to risk for mania, as defined by measures of subsyndromal manic symptoms such as the General Behavior Inventory (GBI; Depue, Krauss, Spoont, \& Arbisi, 1989 ) and the Hypomanic Personality Scale (HPS; Eckblad \& Chapman, 1986). Both measures are well-validated as predictors of bipolar onset (Kwapil et al., 2000; Lewinsohn, Klein, \& Seeley, 2000). Although analog studies of psychiatric disorders have been criticized on many fronts (Coyne, 1994), conjoint studies of those at risk and those diagnosed with the disorder may be important for fully understanding creativity in bipolar disorder - several authors have suggested that vulnerability to mania and mild forms of the disorder are related to enhanced creativity, but that severe episodes of disorder will limit creative accomplishment (cf. Richards, Kinney, Lunde, Benet, \& Merzel, 1988). Indeed, manic episodes may limit the nature of occupational and social opportunities that would contribute to creative accomplishments, and repeated experiences of these lost opportunities may suppress the motivation, self-confidence and hope needed to pursue accomplishments. Moreover, as we discuss below, the mood-stabilizing medications used for treatment of manic episodes may influence some of the cognitive processes related to creativity. Because at-risk samples do not have these same confounds related to the consequences of illness and treatment, they provide a helpful parallel to research with clinical samples.

More broadly, less severe forms of the disorder tend to be more common. For example, whereas bipolar I disorder affects about $1 \%$ of the population, bipolar spectrum disorders may affect about $6.4 \%$ of the population (Judd et al., 2003; Van Meter, Moreira, \& Youngstrom, 2011). Cyclothymic and hypomanic temperaments appear to be even more common (Angst et al., 2010; Karam et al., 2010), and appear to be distributed along a continuum (Prisciandaro \& Roberts, 2011). Affective temperaments thus are an individual difference variable that everyone possesses to different degrees. High levels of cyclothymic temperament might be a diathesis for the development of fully syndromal mood disorder or a prodromal expression of incipient bipolar disorder. The affective temperament itself might be the attribute showing a link to creativity, rather than the mood disorder - conceptually, both creativity and pathology might be outcomes attached to extreme levels of affective temperament.

\subsection{Operationalizing creativity}

Most definitions of creativity emphasize novelty and originality, balanced against utility. That is, creativity can be thought of as the development of novel solutions that work (Runco, 2004). There is no one universally accepted definition of creativity, but rather a multitude of approaches, each with distinct strengths and weaknesses.

Although many would argue that creative accomplishments are the most face valid form of creativity, achieving recognition for creativity may depend on factors beyond creative thought. A dominant approach has been to examine the social and personality predictors of 
lifetime creative accomplishment. To achieve fame, people may need drive and motivation, as well as social opportunities and resources that allow for promoting their work.

Researchers have also considered the abilities that support creative thinking and problemsolving in laboratory paradigms. At a broad level, tasks can be divided into tests of convergent thinking in which there is one correct answer (e.g., anagrams) and tests of divergent thinking designed to measure the ability to generate unique and diverse solutions. Many of these measures are based on conceptual models of creative thought. For example, Mednick (1962) argued that creative thinking stemmed from the ability to combine conceptually distinct associative elements in a novel manner, and the Remote Associates Task (RAT; Mednick \& Mednick, 1967) was designed to measure the ability to generate a broad range of associations. Participants are provided with three words and asked to find a word that is associated with all three (e.g., mower, atomic, foreign as stimuli, power as the answer). Drawing from a model that creativity involves a willingness to consider atypical associations (Eysenck, 1993), the Rosch (1975) category inclusion task involves asking participants to rate how well different elements fit within a category (e.g., bus and camel as examples of vehicles). Willingness to allow atypical exemplars into a category is expected to allow people to consider more unusual, and potentially creative, combinations.

Other tests of divergent thinking provide measures of originality, fluency, and flexibility (Guilford, 1967; Torrance, 1990). For example, in the Unusual Uses Task (Guilford, 1967), participants are asked to suggest as many uses for a common object as they can in a set amount of time. Fluency is scored as the number of nonredundant uses proposed, flexibility as the number of different categories of uses proposed, and originality based on the number of unusual uses proposed. Flexibility may depend on the ability to inhibit a prior response set or to set-shift, so as to be able to generate responses from new categories (Rende, 2000). Hence, set-shifting is considered to be a cognitive capacity that would foster flexibility. Available batteries of divergent thinking include verbal and pictorial measures of originality, fluency, and flexibility in problem-solving.

Researchers have increasingly distinguished two types of processes used to solve creativity problems: (a) analytical, methodical, conscious problem-solving versus (b) insight. Insight can be thought of as the "aha" experience in which the problem solution often emerges quite suddenly, participants are not often consciously aware of the process that was employed to solve the problem, and they often use atypical or distantly related concepts in new combinations (Schooler \& Melcher, 1995). Insight has been studied by asking participants to solve problems that require a shift in strategy to achieve resolution. In one of the oldest insight tasks, participants are given a candle, a box of tacks, and a book of matches and asked to attach the candle to the wall. Most people attempt to attach the candle to the wall using thumbtacks or melted wax-few think to use the box as a candleholder that can be tacked to the wall (Duncker, 1945).

In sum, the creativity literature provides a rich array of paradigms and approaches to assessing different definitions of creativity. One of the troubling features of the field is that the different approaches are often only modestly correlated. For example, divergent thinking measures generally have only modest correlations (Is of about .30) with teacher or peer ratings of creativity and original thinking and to have little relationship with achieving eminence (Batey \& Furnham, 2008). Each approach to creativity has strengths and weaknesses, and so multiple forms of study are likely necessary (Batey \& Furnham, 2008). In the following sections, we will review whether many different aspects of bipolar disorder relate to many different aspects of creativity, as illustrated in Fig. 1. 


\section{Research on whether bipolar disorder is related to creativity}

We begin with the research on famous artists, as this has been a focal point in this literature. We then consider a smaller set of studies on whether bipolar disorder is linked to engaging in creative pursuits, including choosing creative occupations and hobbies. Then, we review findings related to interviewer- and self-ratings of creative accomplishment. Exemplifying the range of methods in the literature, several studies have examined preferences for complex stimuli, an aesthetic preference that has been found to be common among artists. We then turn to the few studies of divergent thinking and other aspects of creative cognition.

\subsection{Does bipolar disorder relate to creative eminence?}

By far the most common approach to understanding whether bipolar disorder is related to creativity has been to study highly famous or recognized creative samples, usually by reviewing biographical materials. Studies of biographical materials suggest that bipolar disorder may have afflicted John Berryman, Robert Lowell, Anne Sexton, Vincent van Gogh, and Robert Schumann, among others (Goodwin \& Jamison, 2007). Several biographical studies are available of mood symptoms among persons with notable creative accomplishments. As shown in Table 1, these studies have provided consistent evidence for elevated rates of bipolar disorder in samples of famous individuals. The Ludwig (1992) study is notable for documenting such patterns in a sample of over 1000 persons. Several of these studies suggest that creativity is particularly likely among those with either mild forms of bipolar disorder (Czeizel, 2001; Jamison, 1989; Wills, 2003) or family histories of bipolar disorder (Juda, 1949) as opposed to full-blown bipolar I disorder. Findings such as this would suggest that those at risk for the disorder may experience some of the creative benefits, even in the absence of more severe symptom expression.

Although most studies of creative eminence have found some overrepresentation of vulnerability to or diagnoses of bipolar disorder, the degree of association noted in these samples has varied dramatically. One potential cause of heterogeneous findings is that raters may differ in how they code diagnosis when biographical materials provide limited detail about mood symptoms. For example, Goodwin and Jamison (2007) noted that Juda (1949) reported an unusually high rate of psychosis in the creative artists, some of whom might have met criteria for bipolar disorder with more data. Beyond this concern, the sample available for biographical studies could be biased, in that people with more profound mood shifts might be more likely to write about their own personal lives or to be written about by others-hence, mood symptoms may influence the availability of biographical materials (Eysenck, 1993). Given concerns about reliability and bias, findings of biographical studies must be considered cautiously.

Fortunately, several researchers have used more careful techniques to evaluate the presence of bipolar disorder, including the use of standardized interviews and questionnaires to assess bipolar symptoms among highly eminent samples. Using structured diagnostic interviews to assess 30 creative writers attending the highly prestigious University of Iowa Writer's Workshop, $43 \%$ were found to meet criteria for bipolar spectrum disorders, as compared to $10 \%$ of a non-creative control group of persons matched for age, gender, and education (Andreasen, 1987a,b). Findings did not appear to be secondary to depression, in that rates of major depressive disorder were not elevated among the writers. Consistent with the idea that milder forms of disorder are particularly beneficial, bipolar II disorder was more common (30\%) among the authors than was bipolar I disorder (13\%). In parallel, accomplished blues musicians have been shown to have higher scores on measures of manic and cyclothymic temperament, rather than more severe diagnosable forms of bipolar disorder (Akiskal \& Akiskal, 1994). 
In sum, in eminent samples, bipolar disorder is clearly overrepresented, particularly when milder forms of the disorder are considered. These findings appear to generalize across methodologies, in that parallel findings emerge from biographical studies and designs that have used more direct assessment of bipolar symptoms.

Across this literature, it appears that less severe forms of disorder are more over-represented than are severe forms of the disorder. Indeed, these paradigms may overestimate the benefits of severe bipolar illness, in that many of the accomplishments could have been achieved before full episodes emerged; no studies to our knowledge have disentangled this issue. A better design might involve assessing creativity before and after severe episodes began to occur.

Beyond the lack of attention to how accomplishment fluctuates over the life course with changing symptoms, achieving eminence may involve many social and personal resources beyond the capacity for creative thought. For example, some people may achieve fame because they are compelling and interesting individuals, or because of exceptional drive. Thus, we turn toward studies that have allowed for more direct assessment of whether bipolar disorder is related to engaging in creative pursuits, rather than studies that have focused on achieving fame.

\subsection{Is bipolar disorder common among in creative occupations?}

Several researchers have considered whether bipolar disorder and risk for bipolar disorder are related to likelihood of choosing a creative occupation. Ludwig (1994) used questionnaires and interviews to assess DSM-III criteria for mood disorders among 59 female fiction writers attending a national writers' conference, as compared to a control group of non-writers matched for age, education, and paternal occupational status. The writers endorsed substantially higher rates of depression (56\%) and mania (19\%) than did the non-writer group (respectively $14 \%$ and $3 \%$ ). Congruent with the idea that family history of the disorder may confer creative benefits, $10 \%$ of the authors reported a parental history of mania compared to $5 \%$ of the non-writers.

Also congruent with patterns observed in the literature on famous individuals, less severe forms of mania may be related to artistic occupations more than severe forms are. In one study, $43 \%$ of artists endorsed cyclothymic traits, a rate that was about four times the rate of those in non-artistic disciplines (Akiskal, Savino, \& Akiskal, 2005). Similarly, Colvin (1995) found higher GBI mania and cyclothymia scores among 40 music students training for careers as solo artists as compared to 40 control participants who were in training for noncreative professions. Overall, studies of those engaged in creative occupations have suggested that bipolar disorder and risk of bipolar disorder are over-represented.

\subsection{Are those with bipolar disorder likely to choose an artistic occupation or hobbies?}

Even if creative samples contain an overrepresentation of bipolar disorder, such studies do not inform as to the proportion of people with bipolar disorder who are creative. That is, within bipolar disorder, is creativity normative or constrained to a subset of people? In one study of 750 psychiatric patients, about $8 \%$ of patients diagnosed with milder bipolar spectrum disorders were rated as being highly creative, compared to less than $1 \%$ of those diagnosed with bipolar I disorder, schizophrenia and unipolar disorder (Akiskal \& Akiskal, 1988). Hence as above, it appears as though creativity might be more apparent in those with milder forms of the disorder. It also appears that most people with bipolar diagnoses are not perceived as being highly creative.

Of course, psychiatric samples may be biased compared to community samples, and so it is particularly important to examine rates of creativity using epidemiological studies that 
provide a representative sample of individuals in the community. In one such analysis, Tremblay, Grosskopf, and Yang (2010) evaluated occupational creativity in the Epidemiological Catchment Area study, which involved a US representative sample of 13,700 persons, 84 of whom met DSM-IIIR diagnostic criteria for a history of bipolar I disorder. Creativity of professions was rated on a scale of 0 to 100 (e.g., writing, painting, lighting design) on the England and Kilbourne (1988) scale. The mean occupational creativity score of those with bipolar I disorder was significantly higher (4.54) than was the mean of those with no diagnosis of bipolar disorder (3.07). Although significant, these findings also suggest that many people with bipolar disorder are not engaged in creative occupations. It is also worth noting the standard error for creativity ratings in the bipolar group was significantly higher than that in the control group. In short, bipolar disorder appears related to a greater likelihood of choosing a creative occupation, but there also appears to be considerable variability in whether people with bipolar disorder will pursue relatively creative occupations.

Nonetheless, given that bipolar disorder is related to choosing creative occupations, a natural question is whether people also engage in more daily creative hobbies. In one study, the Biographical Inventory of Creative Behaviors (Batey, 2007) was used to index participation in 34 different creative tasks over the past 12 months. Higher scores on the HPS were correlated with more engagement in creative daily activities (Furnham, Batey, Anand, \& Manfield, 2008).

\subsection{Does bipolar disorder predict interviewer ratings of creative achievement?}

In one of the most widely cited studies of creativity in bipolar disorder, Richards and her colleagues reported findings using the Lifetime Creativity Scale (Richards, Kinney, Benet, \& Merzel, 1988), a structured interview for assessing lifetime creative accomplishments, as defined by major endeavors that are original and recognized by others as meaningful contributions. The interview covers a range of domains (e.g., producing plays, musical compositions, or visual art work, as well as achieving recognition for this work). Peak lifetime ratings of accomplishment were higher among 33 persons with bipolar disorder than among the controls with no history of mood disorders or schizophrenia (Richards, Kinney, Lunde et al., 1988). Consistent with the creative benefits associated with less severe forms of disorder, the 16 persons with cyclothymia were rated as having greater accomplishments than the 17 persons diagnosed with bipolar I disorder. Indeed, those with bipolar I disorder obtained scores that did not differ from those obtained by the healthy controls. Creative accomplishments were also evaluated among 11 unaffected family members of bipolar probands, and the mean creativity score in this group was higher than the mean of the bipolar disorder sample (Richards, Kinney, Lunde et al., 1988). The creative accomplishments associated with cyclothymia were largely a result of occupational endeavors and were not explained by avocational activities, and they were equally divided between the arts, sciences, humanities, and the social sciences. These findings do not appear to be confounded by current manic symptoms, in that findings of a separate study did not indicate that current manic symptoms as measured by the MMPI-2 (Lumry, Gottesman, \& Tuason, 1982; Post, 1986) correlated with scores on the Lifetime Creativity Scale (Schuldberg, 2010).

\subsection{Do people with bipolar disorder describe themselves as creative?}

Several researchers have examined how people with bipolar disorder rate their creative abilities, most typically using the Adjective Checklist Creative Personality Scale (Gough, 1979) or the What Kind of Person Am I Scale (Khatena \& Torrance, 1976). The former asks people to rate themselves on a set of adjectives measuring inventiveness, originality, and submissiveness (the latter is reverse scored); the latter includes a broader array of traits 
believed to relate to creativity, including (Lack of) Acceptance of Authority, Self-

Confidence, Inquisitiveness, Awareness of Others, and Disciplined Imagination.

As shown in Table 2, among students, risk for mania tends to correlate with positive selfratings of creative abilities on scales such as the Adjective Checklist Creative Personality Scale (Furnham et al., 2008; Schuldberg, 2001; Shapiro \& Weisberg, 1999). The effects of mania risk appear more robust than those for depression or impulsivity (Schuldberg, 2001). Indeed, only one study failed to replicate the correlation of mania risk with self-rated creativity, and that study was characterized by a sample that was constrained in variability by virtue of being entirely comprised of artists (Frantom \& Sherman, 1999).

In contrast to the evidence that those at risk for the disorder see themselves as creative, the only available study of a diagnosed sample did not find elevated self-ratings of creativity (Santosa et al., 2007). These findings echo those with other creativity measures, in that milder expressions and risk for bipolar disorder may be more related to creativity than are more severe forms. Below, we will consider how mood state might influence these ratings.

\subsection{Do people with bipolar disorder prefer stimuli that creative people tend to prefer?}

Several studies of bipolar disorder have included the Baron Walsh Art Scale (BWAS), a measure of preference for novel and complex figures over simple and symmetrical figures that has been shown to be correlated with choosing creative occupations (Barron, 1963). People with bipolar disorder (Santosa et al., 2007; Simeonova, Chang, Strong, \& Ketter, 2005), their offspring (Simeonova et al., 2005), and those with subsyndromal symptoms of mania (Rawlings \& Georgiou, 2004; Schuldberg, 2001) report preferring novel and complex figures more than simple figures. Indeed, in one study, BWAS scores were comparable to those observed in a sample of students enrolled in graduate programs in fine arts, creative writing, and product design (Santosa et al., 2007).

Two caveats are important in regard to findings with the BWAS scale. First, it appears that the correlation between BWAS scores and bipolar disorder are largely mediated by tendencies to endorse a pronounced dislike for the simple figures (Santosa et al., 2007; Simeonova et al., 2005), and previous research suggests that dislike of the simple figures is robustly correlated with measures of negative emotionality (King, Curtis, \& Knoblich, 1991; Strong et al., 2007). Indeed, within bipolar disorder, higher BWAS scores have been shown to be related to Neuroticism scores (Srivastava et al., 2010). Beyond the need to disentangle negative affectivity from results, in one study of youths with bipolar disorder, BWAS scores tended to correlate negatively with years of illness, $r=-.53$ (Simeonova et al., 2005), suggesting that it may be important to attend to how these preferences change with repeated experiences of illness.

\subsection{Does bipolar disorder relate to divergent thinking ability?}

In a meta-analysis of 36 studies, psychopathology scores were found to be robustly related to higher scores on measures of divergent thinking, $g=.50$ (Ma, 2009). Fewer studies have examined divergent thinking in bipolar disorder. Findings of one study indicated that mania risk, as measured with the HPS, was related to higher fluency scores on the Unusual Uses Test, $r=.20$ (Furnham et al., 2008). Scores for flexibility and originality were not reported in this study, though.

Findings regarding divergent thinking levels among persons diagnosed with bipolar disorder are less positive. Santosa et al. (2007) compared 49 persons with remitted bipolar disorder to participants with remitted major depressive disorder $(n=25)$, a control group with no history of mood disorder $(n=32)$, and a creative control group of graduate students in creative disciplines $(n=47)$ using the Verbal and Figural subscales of the Torrance Tests of 
Creative Thinking. Neither the bipolar disorder nor the creative control group demonstrated elevated Torrance Verbal scores. The bipolar disorder group obtained a mean on the Figural subscale that was between that of the creative controls and the healthy controls, but did not differ significantly from the mean of either of those groups. This study provided no evidence for elevations in divergent thinking among those diagnosed with bipolar disorder.

Researchers have also tested the ability to set-shift among persons diagnosed with bipolar disorder. Research suggests that adults and children diagnosed with bipolar disorder (Dickstein et al., 2007; Gorrindo et al., 2005), and even relatives of people with bipolar disorder perform more poorly on tests of attentional set-shifting or reactive flexibility (Clark, Sarna, \& Goodwin, 2005). This deficit would be expected to interfere with flexibility.

In sum, divergent thinking has been found to be positively related to mania risk, but was not found to be elevated among persons diagnosed with bipolar disorder. Indeed, bipolar disorder appears to be related to deficits in set-shifting, which might be expected to impair flexibility.

\subsection{Summary of the association between bipolar disorder and creativity}

Before considering potential mechanisms driving creativity, it is worth pausing to review the evidence linking bipolar disorder with creativity. A large literature suggests that many famous artists, musicians, and authors have gone through periods of manic symptoms, particularly when very mild manic symptoms are considered. Similar profiles emerge in biographical studies and those that have directly assessed bipolar symptoms among highly eminent samples. Investigations have also found that bipolar spectrum disorders and family history of bipolar disorder are related to high levels of lifetime creative accomplishment. Several studies suggest that people with bipolar disorder and those with subsyndromal manic traits prefer complex stimuli (a correlate of choosing a creative occupation), and they are more likely to choose creative occupations than are others. On the whole, this set of findings provides strong support for links of bipolar disorder of varying levels of expression with lifetime creative accomplishments and creative pursuits.

Beyond the studies of creative lifetime accomplishments, findings have tended to be more discrepant. Risk for mania appears related to higher self-ratings of creativity, and also the ability to generate novel solutions on laboratory creativity tasks, such as the Unusual Uses Test. In contrast, persons diagnosed with bipolar disorder do not rate themselves as highly creative or attain high scores on the Torrance creativity tasks, but rather, show deficits in set shifting. Hence advantages in any form of creative process appear more linked to risk for the disorder than to diagnosed disorder. The inability to document advantages in creative thinking among diagnosed samples is a clear contrast with the data on lifetime accomplishments in creative endeavors.

How can these discrepancies across forms of creativity be understood? It is possible that creativity is not a trait-like feature of bipolar disorder, but rather ebbs and flows in a statelike manner. Eminence and lifetime accomplishment could be driven by intermittent bouts of creative thought, perhaps related to mood variability among those with bipolar disorder (Lovejoy \& Steuerwald, 1995). Hence, as we consider mechanisms, we will attend to both trait-like and state-dependent mechanisms linking bipolar disorder to creativity.

\section{What mechanisms could promote creativity in bipolar disorder?}

Choosing a creative occupation and achieving success in that domain could be the end product of many different qualities of an individual or his or her context. Here, we focus on 
personality, motivational, and affective predictors of creativity, and we consider how each of these areas might inform research on bipolar disorder.

\subsection{Personality traits related to creativity}

We begin by considering the personality traits associated with choosing a creative occupation and then we turn to predictors of creative accomplishments. In a meta-analysis of 29 studies involving 4397 participants on personality traits associated with choosing artistic occupations, Feist (1998) found the largest effect sizes for NEO dimensions of impulsivity (mean $d=.75$ ) and the inverse, absence of conscientiousness (mean $d=-.60$ ). Parallel findings emerged from those studies using the California Psychological Inventory: Traits related to impulsivity were robustly related to choosing an artistic occupation. It is possible that impulsivity may help promote expressiveness without constraint, fostering the emergence of more unique products.

Several studies have documented heightened impulsivity within bipolar disorder, during manic episodes (Swann, Dougherty, Pazzaglia, Pham, \& Moeller, 2004) as well as during remission (Peluso et al., 2007; Swann, Anderson, Dougherty, \& Moeller, 2001; Swann et al., 2004). These findings have been documented using both self-report as well as behavioral measures of impulsivity (Strakowski et al., 2009, 2010). Perhaps of most importance, studies now suggest that impulsivity can predict the onset of disorder among those with subsyndromal symptoms (Alloy et al., 2009; Kwapil et al., 2000).

Beyond the role of impulsivity in occupational choice, Feist (1998) also found that persons in creative occupations obtained consistently higher scores on measures of Openness to Experience $(d=.44)$. Openness to experience includes has been defined as motivation to pursue novel ideas and experiences (McCrae \& Costa, 1997). Openness also correlates with a tendency to value thinking and reasoning (DeYoung, Quilty, \& Peterson, 2007), and this facet appears to be correlated with creativity (Carson, Higgins, \& Peterson, 2003). Regardless of the mediators, Openness to Experience has been related to many other facets of creativity as well, including creative accomplishment, engagement in creative daily activities, and divergent thinking (McCrae \& Ingraham, 1987; Silvia, Nusbaum, Berg, Martin, \& O'Connor, 2009).

Several studies have suggested that Openness to Experience is elevated among individuals with bipolar disorder compared to controls with no mood disorder (Barnett et al., 2010) and to those with depression (Klein, Kotov, \& Bufferd, 2011). Openness to Experience also appears to be positively correlated with risk for mania (Meyer, 2002). In one study, Openness to Experience statistically mediated the link of mania risk (HPS scores) with engagement in daily creativity activities (Furnham et al., 2008), but not with divergent thinking or self-rated creativity. That is, among those at risk for mania, Openness to Experience may relate to enjoying creative activities and occupations more than to divergent thinking.

Aside from literature on predictors of occupational choice, a substantial literature is available on personality traits that drive success in creative pursuits. It has been argued that commitment and effort are major predictors of success in creative efforts (Sternberg, 2003). In her studies of famous scientists and artists, Anne Roe $(1946,1951)$ noted that their most distinctive characteristic was their willingness to work hard and long hours. In metaanalyses of the predictors of creative accomplishments in both science and arts, Feist (1998) identified substantial evidence for the importance of ambition and drive. Biographical studies of influential musicians, visual artists, and writers reveal that most produce their creative output (whether commercially recognized or not) only after many years of practicing their skill (Sternberg, 2006). Parallel work in the education domain has found that 
one of the best predictors of scholastic accomplishment is high goal-setting (Locke \& Latham, 2002). Hence, dedication and persistence toward creative goals appears to be a prerequisite for accomplishment in most cases, and this dedication may derive largely from ambition. Of course, ambition without confidence would hardly inspire someone to work hard, and so it is not surprising that confidence also relates to success in creative pursuits (Feist, 1998; McCrae \& Ingraham, 1987).

Considerable evidence exists that bipolar disorder is related to a drive to succeed in goals. Several studies have documented that bipolar disorder is related to perfectionistic attitudes toward goals (Spielberger, Parker, \& Becker, 1963) and to self-critical attitudes about the need to attain goals (Scott, Stanton, Garland, \& Ferrier, 2000; Wright, Lam, \& NewsomDavis, 2005). In a series of eight samples at-risk for bipolar disorder (Carver \& Johnson, 2009; Gruber \& Johnson, 2009; Johnson \& Carver, 2006; Johnson, Carver, \& Siegel, 2011) and in one diagnosed sample of people with bipolar disorder (Johnson, Eisner, \& Carver, 2009), those prone to mania were found to endorse extremely elevated lifetime ambitions for success. Elevated lifetime ambitions have also been found to predict the onset of disorder among those at risk by virtue of subsyndromal symptoms (Alloy et al., in press). In each study, mania-proneness was related to extrinsically-oriented ambitions to achieve the recognition of others, through popular fame and financial success. This tendency to endorse high extrinsically-oriented ambitions appears to be a trait-like feature of the disorder- it is present during remission and after controlling for subsyndromal symptoms. It also does not appear to be related to depressive symptoms (Carver \& Johnson, 2009; Gruber \& Johnson, 2009; Johnson \& Carver, 2006; Johnson et al., 2011). These heightened ambitions, coupled with a sense of confidence, might provide the fuel for people to persevere with difficult to accomplish goals. Indeed, findings of two laboratory studies indicate that given opportunities for reward, people with bipolar disorder persevere as tasks become difficult more than do controls (Harmon-Jones et al., 2008; Hayden et al., 2008).

Several studies also suggest that bipolar disorder is related to elevations of confidence, whether measured for immediate (Meyer, Beevers, \& Johnson, 2004) or lifetime goals (Meyer \& Krumm-Merabet, 2003). Confidence appears particularly elevated once people with bipolar disorder are in a good mood (Eisner, Johnson, \& Carver, 2008; Stern \& Berrenberg, 1979). Hence, bipolar disorder appears related to heightened ambitions, and during positive moods, a belief that one can succeed in difficult goals. One would expect that these qualities would contribute to accomplishment.

Consistent with a greater focus on achievement, large-scale studies have documented higher rates of accomplishment in first degree relatives of those with bipolar disorder compared to the general population (Coryell et al., 1989; Tsuchiya, Agerbo, Byrne, \& Mortensen, 2004). One idea is that family members may experience the heightened ambition, and without the interference from symptoms, this translates into unusual levels of success (Johnson, 2005). Heightened levels of accomplishment also appear to be a pre-onset characteristic of bipolar disorder - a recent study found that extremely high levels of scholastic accomplishment were predictors of onset of disorder (MacCabe et al., 2010).

In sum, the most robust personality correlates of choosing a creative occupation impulsivity and openness to experience - are well-documented as related to bipolar disorder. Success in creative endeavors appears highly related to drive and ambition-two traits that are also consistently documented as related to bipolar disorder and risk for disorder. Taken together, there is considerable evidence that the personality and motivational correlates of bipolar disorder might help explain the enhanced likelihood of choosing a creative career and of dedicating oneself to achieving creative success. 


\subsection{Affect and creativity}

Because bipolar can involve depressive episodes as well as manic symptoms, we consider the potential role of negative affectivity and depression. We then consider the role of positive emotions and manic symptoms with regard to creativity.

It has been theorized that negative emotions may be useful for creativity, and particularly for critical thinking (Csikszentmihalyi \& Rathunde, 1998; Rathunde, 2000) and perseverance (De Dreu, Baas, \& Nijstad, 2008). This idea has been a major focus of research, with more than 63 studies considering the role of affect on creativity (Baas, De Dreu, \& Nijstad, 2008). Despite theory, findings of two meta-analyses have identified no effect of negative affect or sadness on creativity tasks (Baas et al., 2008; Davis, 2009).

Beyond negative affective states, it has long been argued that depression might be related to higher creativity. Researchers conducting biographical studies, for example, have noted high rates of depression in authors, musicians, and other artistic groups (Jamison, 1993; Ludwig, 1992 although see Andreasen, 1987a,b for a nonreplication). Despite this, in studies with direct assessments of depression, depressive symptoms were negatively related to lifetime ratings of creativity (Schuldberg, 2010), to measures of divergent thinking such as the Torrance Creativity scales (DeMoss, Milich, \& DeMers, 1993) and to self-ratings of creativity (Schuldberg, 2010). In other studies with objective measures of depression, a history of depression was uncorrelated with measures of creative accomplishment, divergent thinking, or investment in creative pursuits (Silvia \& Kimbrel, 2010; Verhaeghen, Joormann, \& Khan, 2005). Given these findings, it would seem unlikely that the elevations of creativity within bipolar disorder would be explained by negative affectivity or depressive symptoms.

Positive emotional states, in contrast, may broaden attention and thinking, widening the array of percepts, thoughts, and images that come into awareness (Isen \& Daubman, 1984; Isen, Daubman, \& Nowicki, 1987; Isen, Johnson, Mertz, \& Robinson, 1985). Fredrickson's broaden-and-build theory of positive emotions (Fredrickson, 1998, 2001; Fredrickson, Cohn, Coffey, Pek, \& Finkel, 2008) proposed that the momentarily broadened mindsets triggered by positive emotions have a range of positive consequences, including enhanced creativity and cognitive flexibility. For instance, experimentally induced positive emotions - relative to induced neutral and negative states - broaden the scope of people's visual attention, an effect shown through behavioral tests (Fredrickson \& Branigan, 2005; Rowe, Hirsh, Anderson, \& Smith, 2007), eye-tracking (Wadlinger \& Isaacowitz, 2008) and now through brain imaging (Schmitz, De Rosa, \& Anderson, 2009; Soto et al., 2009). Positive emotions relax inhibitory control and open awareness to unattended information (Schmitz et al., 2009). With greater access to both attended and unattended information, it has been argued that positive emotions facilitate the ability to "see the big picture" and to process information at a global level (Fredrickson \& Branigan, 2005). Induced positive emotions also expand people's repertoires of desired actions (Fredrickson \& Branigan, 2005), their openness to new experiences (Kahn \& Isen, 1993), and their attention to peripheral details of memories (Talarico, Bernsten, \& Rubin, 2009). Creativity appears to be facilitated when people have broader attention to both internal and external stimuli (Carson et al., 2003; Folley \& Park, 2005).

Drawing on this literature, one would expect that positive affect would enhance performance on measures of creativity. Consistent with this, positive affect is related to better performance on the Remote Associates Test (Fodor \& Greenier, 1995; Isen et al., 1987; Rowe et al., 2007) and other measures of the ability to generate unusual word associations (Isen et al., 1985), to ability to solve insight problems such as Duncker's (1945) candle task (Isen et al., 1987; Topolinski \& Reber, 2010), as well as to willingness to allow more 
atypical exemplars on Rosch's (1975) category inclusion task (Isen \& Daubman, 1984). Hence considerable evidence suggests that positive affect enhances creativity.

Indeed, in a recent meta-analysis of the effects of positive mood on creativity tasks, Baas, De Dreu, \& Nijstad (2008) documented a small to moderate effect size for positive moods enhancing creativity ( $\mathrm{r}=.15, \mathrm{~N}=5165$ participants across 63 studies). Effects were larger when experimenters used mood induction procedures rather than relying on naturalistic ratings of mood. Large effects were observed for highly activated positive mood states, such as enthusiasm. Low arousal positive mood states, such as serenity, did not relate to enhanced creativity. That is, creativity effects appear to be dependent on the combination of high arousal and positive affect.

In a separate meta-analysis, Davis (2009) provided a more refined understanding of the types of creativity and the levels of positive affect that were most relevant. Creativity tasks were divided into those that involved idea generation (divergent thinking measures, categorization tasks, and remote association measures) and those that involved problemsolving (defined by tasks that involved identifying one best solution from a set of possibilities). The benefits of positive affect appeared specific to idea-generation as compared to problem-solving. Even in considering idea generation, though, positive affect had curvilinear effects on creativity: moderately positive moods were associated with better performance than were mildly positive moods, but intensely positive moods were detrimental compared to moderately positive moods.

Given the substantial evidence that positive mood states appear to enhance performance on tasks measuring cognitive flexibility and creativity, we turn toward the role of positive moods in bipolar disorder. One of the common symptoms of manic episodes is intense euphoria. Beyond episodes, positive affectivity is elevated for some people with bipolar disorder during remission (Gruber, Johnson, Oveis, \& Keltner, 2008; Kwapil et al., 2000; Lovejoy \& Steuerwald, 1995; Myin-Germeys, van Os, Schwartz, Stone, \& Delespaul, 2001; Oedegaard, Syrstad, Morken, Akiskal, \& Fasmer, 2009). Others with bipolar disorder, though, experience diminished positive affectivity and indeed negative affect, in part due to chronic subsyndromal depressive symptoms (Judd et al., 2002). Even among those who tend to experience lower trait-like positive affectivity, many experience mood lability and intermittent periods of heightened mood state (Myin-Germeys et al., 2001). It has been suggested that these types of shifts in affect might contribute to creative processes (Srivastava \& Ketter, 2010).

Several studies suggest that people with bipolar disorder believe that their positive moods and manic symptoms can enhance creativity. Among 31 highly creative outpatients diagnosed with bipolar disorder, $83 \%$ reported that mania was related to at least some increase in their creativity (Jamison, Gerner, Hammen, \& Padesky, 1980). In a study of 47 accomplished writers and artists, $89 \%$ described intense creative productivity during periods of high mood and energy (Jamison, 1989). Even when less accomplished samples are interviewed, people with mood disorders believe their creativity is heightened during periods of mildly positive mood states (R. Richards \& Kinney, 1990). Consistent with beliefs that mania enhances creativity, several case reports have noted client concerns that lithium might deter creativity for some, but not all clients (Polatin \& Fieve, 1971; Schou, 1968). Given, though, that over-confidence is one of the core symptoms of mania, it is important to consider whether mood-state effects on creativity can be documented using measures other than self-reported creativity.

There is some evidence from biographical studies that manic symptoms may bolster creative productivity. During a three- year period in which she was thought to have suffered from 
hypomanic symptoms, Emily Dickinson generated poems at ten times the rate observed during other periods of her life (Ramey \& Weisberg, 2004). Slater and Meyer (1959) used Robert Schumann's letters, which often disclosed his mood state, to track the link between his mood states and his creative output. Schumann clearly composed more pieces during manic periods. As an index of the quality of this output, Weisberg (1994) also examined the number of recordings of pieces that were available (presumably driven by popular demand for those pieces-see Repp, 1994 for a criticism of this index). Mood state during composition was unrelated to the number of recordings available. Hence, Weisberg concluded that manic symptoms did not bolster the quality of compositions even though it did seem to bolster the number of compositions. It is also worth noting that not all evidence suggests heightened productivity during manic periods. For example, in a biographical study of Virginia Woolf, productivity was evident only during her well periods (Figueroa, 2005). Hence it does not appear universal for mania to enhance productivity, but there is some evidence that at least a subset of people with bipolar disorder generatemore products, if not higher quality products, during manic episodes.

A small number of studies have tested cognitive abilities related to creativity during manic episodes. People who were experiencing manic episodes have been found to obtain higher fluency scores - that is, they provided more word associations to a given stimulus word than did healthy controls and persons hospitalized for other psychiatric disorders (Levine, Schild, Kimhi, \& Schreiber, 1996). That people produce a lot of words when manic is not surprising given that racing thoughts and pressured speech are symptoms of mania. In parallel, Andreasen and Powers (1975) used an object sorting task to measure conceptual over-inclusiveness, defined as the tendency to allow a broader range of concepts into a given category. Mean conceptual over-inclusiveness scores were as high among 16 people hospitalized for mania as the scores of a highly creative sample, and the scores of both of those groups were higher than those of a comparison group of persons hospitalized for schizophrenia. In both studies, though, persons experiencing mania generated many more errors than other groups (Andreasen \& Powers, 1975; Levine et al., 1996).

Consistent with the idea that mania enhances fluency, two studies have found that associational fluency increased after people with bipolar disorder discontinued lithium (Kocsis et al., 1993; Shaw, Mann, Stokes, \& Manevitz, 1986). The effects of lithium on diminished associational fluency may be related to mania symptoms, in that among healthy undergraduates, a two-week trial of lithium did not influence fluency on an association task (Judd, Hubbard, Janowsky, Huey, \& Takahashi, 1977). The effects of lithium on fluency, then, are consistent with the idea that manic symptoms can increase fluency.

Given the evidence that fluency increases during mania, one question is whether all symptoms of mania are equally relevant to creative thinking. Periods of manic symptoms differ in whether they reach a severe level (a manic threshold), but also in the nature of the symptoms evident in a given episode (Cassidy, Forest, Murry, \& Carroll, 1998). In interviews concerning the links of symptoms with creativity, eminent writers and artists reported differed in their experiences of different symptoms. Whereas more than $80 \%$ reported symptoms such as high mood, energy, and decreased need for sleep, less than half reported experiencing more destructive symptoms such as hyper-sexuality and overspending. Moreover, the writers and artists reported that high mood, energy, and decreased need for sleep benefited creativity, but that other manic symptoms, such as hypersexuality or over-spending, were not beneficial to creativity (Jamison, 1989). In a study of persons at risk for mania, Shapiro and Weisberg (1999) examined which subsyndromal symptoms of mania, as measured by the GBI, were related to self-ratings on the Adjective Checklist Creative Personality Scale (ACL-CPS; Gough, 1979). Creativity was specifically related to more adaptive symptoms of mania, such as increased activity, less need for sleep, 
excitement, engagement in new activity, enhanced thinking, and faster thought, as opposed to symptoms such as anger, hypersexuality, and poor judgment. These findings would suggest that mildly positive moods and energy increases may be more beneficial than full manic episodes. This profile fits with case reports that lithium can increase productivity for those with severe symptoms of bipolar disorder (Schou, 1979). Naturalistic and treatment studies, then, suggest that if manic symptoms provide an advantage for creativity, it may be the mild manic symptoms that do so. That is, positive affect and energy are beneficial, but treating severe symptoms could enhance creativity.

There is some evidence that mildly positive mood states can be beneficial to creativity among those at risk for mania. In one study, college students either high or low in hypomanic traits as measured using the Millon Clinical Multiaxial Inventory were randomly assigned to a positive mood induction of writing about a peak accomplishment or to a neutral mood induction of writing about a typical day (Fodor, 1999). All participants then completed the Remote Associates Test. The interaction of mood state and hypomanic traits was significant; positive moods related to higher creativity only for those with high scores on the measure of hypomanic traits. These early results suggest that amongst people at risk for mania, cognitive flexibility may be particularly enhanced by positive mood states.

Further research is needed on the breadth of creative process enhanced by mood state, as well as the effects of different forms and severities of symptoms. For now, it appears that certain forms of creativity, such as fluency and conceptual inclusiveness, are higher during mania than during euthymia, but that mania also may be related to more errors on such tasks. Other studies, though, suggest that happiness and energy have more positive effects on creativity than do other manic symptoms.

\subsection{Summary of potential mechanisms}

Basic literature outside of bipolar disorder suggests an array of personality and affective mechanisms that foster creativity. Different aspects of creativity, though, are predicted by different affective, motivational, and personality qualities. Choosing a creative occupation appears related to impulsivity and openness to experience, whereas achieving fame within that occupation seems more related to ambition and confidence. Divergent thinking and insight appear to be fostered by moderate levels of positive affect. Clearly, a range of mechanisms are relevant for creativity. One caveat is that studies have failed to find support for the idea that depression enhances creativity (Baas et al., 2008; Davis, 2009).

We have reviewed evidence that bipolar disorder is related to many of these precursors to creativity, including elevated tendencies toward impulsivity, openness to experience, ambition, confidence, and positive mood states. Somewhat surprisingly, very little is known about which of these variables actually do mediate creative outcomes associated with bipolar disorder - that is, few studies are available that consider affect, cognition, and personality along with indices of creativity. Available evidence suggests that milder forms of bipolar disorder and risk for mania are related to greater lifetime creative accomplishments, which might be fostered by the ambition and goal-directedness related to this disorder. People with bipolar disorder tend to be more likely to pursue creative occupations, and comfort in these areas could be related to impulsivity and openness to experience, and preferences for complex stimuli. Evidence regarding creative cognition is particularly complex. Advantages for fluency are apparent in for diagnosed samples during mania, but have not been shown for persons in remission from bipolar disorder. It will be important to consider the benefits of minor shifts in positive affect among those diagnosed with bipolar disorder, as one study to date suggests this can bolster divergent thinking among those at risk for mania. Personality and affective mechanisms involved in the creativity of people with bipolar disorder would seem to be a ripe area for future research. 


\section{Toward a research agenda}

Here, we turn to a set of concerns that lay the foundation for a research agenda. On the whole, perhaps the most major concerns are the limited number of studies and the small sample sizes in those studies. Beyond a general call for more research, though, we turn toward particular issues that merit attention in the next wave of research.

To begin, several important approaches to measuring creativity have not been used in bipolar disorder, including measures of insight, objective ratings of a creative product (Hocevar \& Bachelor, 1989), or cognitive variables related to creativity such as cognitive inhibition (Carson et al., 2003). It would also seem important to gather data using a range of creativity measures, and we can only identify one study using a profile approach to creativity within the bipolar field (Santosa et al., 2007). In the face of the compelling studies of lifetime accomplishment, the absence of research using carefully validated measures of creative problem-solving is remarkable. Stated differently, the literature provides clear evidence that mild forms of bipolar disorder increase the odds that one will be a creative person. The literature provides few clues, though, about the creative processes that contribute to this level of accomplishment within bipolar disorder.

As researchers examine creative processes, several sources of inter-individual variability in bipolar disorder must be considered. To begin, creativity may decline over time for those diagnosed with bipolar disorder - the neurocognitive, psychological, and social consequences of bipolar disorder could diminish creative cognition, confidence, and motivation. In the only study to examine developmental course, preferences for complex figures were lower among those adolescents who had been ill for more years (Simeonova et al., 2005). It is unknown if this pattern is observed across measures of creativity. If it does generalize, research is needed on how to protect creative accomplishment as repeated experiences of symptoms unfold.

Early evidence suggests that fluency and unusual thinking may be enhanced by manic symptoms. To better understand these cognitive shifts, researchers will need to include indices of the utility of creative products that are generated, as some evidence suggests that some of the categorizations and associations produced during mania may be too unusual to be effective. This may help explain how manic episodes relate to one index of creativity (fluency), but not others, such as lifetime accomplishment and self-rated creativity. It also appears that certain symptoms of mania, such as positive affect and energy, may be more beneficial than other symptoms. Developing a better understanding of the nature of creative thought during mania is paramount for addressing concerns about whether intervention will interfere with creativity.

Related to state-dependent changes, little is known about the effects of medications. Some evidence suggests that lithium can lower fluency for those with bipolar disorder. Stoll, Locke, Vuckovic, and Mayer (1996) described seven clients who felt divalproax was more protective for creativity than lithium was, but we are unaware of a single trial that has compared effects of different mood-stabilizing medications on creativity measures.

In short, there is reason to believe that for a person with bipolar disorder, creativity may shift with years of the illness, with fluctuations in mood and symptoms, and with medications. Disentangling these effects, though, requires longitudinal research.

Another concern is that most researchers have compared mean creativity levels between groups, without much attention to within-group variability. It is worth considering that bipolar disorder might be associated with an increase in the number of extreme acts of creativity - both successful and failed - rather than change in the average amount of 
creativity. That is, the standard deviation of creativity scores might be larger among people affected by bipolar disorder. If so, then this would mean that acts of extreme, "genius" creativity would be more common than would be expected based on average ability levels. The unfortunate corollary to this model is that bipolar disorder might also be associated with an opposite tendency to have spectacular failures, counterbalancing the increase in successes. In essence, this model posits that bipolar disorder is like a speculative stock, with greater volatility magnifying the chances of outstanding returns, as well as failure. Another corollary is that standard error terms would be higher for bipolar samples than for other samples. Several researchers have reported standard error terms for creativity measures that appear larger in the bipolar compared to the control samples (Shapiro \& Weisberg, 1999; Simeonova et al., 2005; Tremblay et al., 2010 but see Richards, Kinney, Benet, \& Merzel, 1988). Larger standard errors could increase the variability in whether statistical tests achieved significance, resulting in more discrepant results across studies. Beyond the conceptual significance of greater variability, this issue might mandate larger sample sizes, as well as attention to the variables that differentiate creativity levels within bipolar disorder.

In considering variability of creativity within bipolar disorder, people with bipolar disorder differ greatly in their comorbid conditions, impulsivity, motivation, drive, confidence, and positive affectivity. Each of these characteristics is likely to influence creativity. Research is needed that considers how variations in these characteristics might relate to creativity. Indeed, as noted above, many theorists assert that categorical bipolar disorder diagnoses misrepresent fundamental dimensionality underlying bipolar disorder phenomena. From this viewpoint, quantitative measures of traits and temperaments along with appropriate quantitative measures of affective state may the most fruitful independent variables in future investigations.

On the whole, it is time for a more refined approach, in which researchers consider processes that contribute to the overrepresentation of forms of bipolar disorder among highly creative persons. Such an approach must consider inter- and intra-individual variability within bipolar disorder.

\section{Conclusions}

We believe that further research is important. Consumers often believe that creative benefits of this disorder stem from cognitive processes that emerge during mania. This belief, which may deter treatment seeking, may not be true. Several studies suggest that milder symptoms, such as happiness and energy, may be more crucial for creativity than severe symptoms.

Other findings indicate that creativity may be common among family members and those at risk for the disorder who do not experience manic or hypomanic episodes. This set of results makes all the more salient the need to conduct the next wave of research on creativity in bipolar disorder. As part of this research agenda, we believe researchers should conduct studies that:

- include a broad array of measures of creativity,

- evaluate cognitive strengths that might promote creativity,

- attend to variability within bipolar disorder due to the course of disorder, medication profiles, comorbid conditions, and mood state, and

- consider whether associated features of the disorder, such as motivation, impulsivity, or positive affectivity can help explain creativity within bipolar disorder.

We believe that such a research agenda is particularly important to pursue given that the findings on creativity provide hope of reducing stigma in bipolar disorder. 


\section{References}

Akiskal HS, Akiskal K. Reassessing the prevalence of bipolar disorders: Clinical significance and artistic creativity. Psychiatrie et Psychobiologie. 1988; 3 (SPEC. ISS.).

Akiskal HS, Akiskal KK. Tempéraments et humeur des musiciens de blues. Nervure. 1994; 8(28-204)

Akiskal HS, Akiskal KK, Haykal RF, Manning JS, Connor PD. TEMPS-A: Progress towards validation of a self-rated clinical version of the temperament evaluation of theMemphis, Pisa, Paris, and San Diego autoquestionnaire. Journal of Affective Disorders. 2005; 85(1-2):3-16. [PubMed: 15780671]

Akiskal HS, Pinto O. The evolving bipolar spectrum. Prototypes I, II, III, and IV. The Psychiatric Clinics of North America. 1999; 22(3):517-534. [PubMed: 10550853]

Akiskal KK, Savino M, Akiskal HS. Temperament profiles in physicians, lawyers, managers, industrialists, architects, journalists, and artists: A study in psychiatric outpatients. Journal of Affective Disorders. 2005; 85(201-206)

Alloy LB, Bender RE, Wagner CA, Whitehouse WG, Abramson LY, Hogan ME, et al. Bipolar spectrum-substance use co-occurrence: Behavioral approach system (BAS) sensitivity and impulsiveness as shared personality vulnerabilities. Journal of Personality and Social Psychology. 2009; 97(3):549-565. [PubMed: 19686007]

Alloy LB, Abramson LY, Nusslock R, Urosevic S, Jager HS, Whitehouse WG, Hogan M. Progression along the bipolar spectrum: Longitudinal study of predictors of conversion from bipolar spectrum conditions to bipolar I and II disorders. (in press).

American Psychiatric Association. Diagnostic and statistical manual of mental disorders. 4th edition, text revision. Washington, DC: Author; 2000.

Andreasen CN. Creativity and mental illness: Prevalence rates in writers and their first-dregree relative. The American Journal of Psychiatry. 1987; 144(10):1288-1292. [PubMed: 3499088]

Andreasen NC. Creativity and mental illness: Prevalence rates in writers and their first-degree relatives. The American Journal of Psychiatry. 1987; 144(10):1288-1292. [PubMed: 3499088]

Andreasen NJ, Powers PS. Creativity and psychosis: An examination of conceptual style. Archives of General Psychiatry. 1975; 32(1):70-73. [PubMed: 1111477]

Angst J, Felder W, Frey R, Stassen HH. The course of affective disorders. I. Change of diagnosis of monopolar, unipolar, and bipolar illness. Archiv für Psychiatrie und Nervenkrankheiten. 1978; 226(1):57-64.

Angst J, Gamma A, Benazzi F, Ajdacic V, Eich D, Rossler W. Toward a redefinition of subthreshold bipolarity: Epidemiology and proposed criteria for bipolar-II, minor bipolar disorders and hypomania. Journal of Affective Disorders. 2003; 73(1-2):133-146. [PubMed: 12507746]

Angst J, Meyer TD, Adolfsson R, Skeppar P, Carta M, Benazzi F, et al. Hypomania: A transcultural perspective. World Psychiatry. 2010; 9(1):41-49. [PubMed: 20148160]

Baas M, De Dreu CKW, Nijstad BA. A meta-analysis of 25 years of moodcreativity research: Hedonic tone, activation, or regulatory focus? Psychological Bulletin. 2008; 134(6):779-806. [PubMed: 18954157]

Barnett JH, Huang J, Perlis RH, Young MM, Rosenbaum JF, Nierenberg AA, et al. Personality and bipolar disorder: Dissecting state and trait associations between mood and personality. Psychological Medicine. 2010; 41(8):1596-1604.

Barron, F. Barron-Welsh art scale, a portion of the Welsh figure preference test. Palo Alto, CA: Consulting Psychologists Press; 1963.

Batey, M. A psychometric investigation of everyday creativity. London, UK: University College; 2007.

Batey M, Furnham A. The relationship between measures of creativity and schizotypy. Personality and Individual Differences. 2008; 45(8):816-821.

Berk M, Berk L, Castle D. A collaborative approach to the treatment alliance in bipolar disorder. Bipolar Disorders. 2004; 6(6):504-518. [PubMed: 15541066]

Berk M, Dodd S. Bipolar II disorder: A review. Bipolar Disorders. 2005; 7(1):11-21. [PubMed: 15654928] 
Birmaher B, Axelson D, Goldstein B, Strober M, Gill MK, Hunt J, et al. Four-year longitudinal course of children and adolescents with bipolar spectrum disorders: the Course and Outcome of Bipolar Youth (COBY) study. The American Journal of Psychiatry. 2009; 166(7):795-804. [PubMed: 19448190]

Carson SH, Higgins DM, Peterson JB. Decreased latent inhibition is associated with increased creative achievement in high-functioning individuals. Journal of Personality and Social Psychology. 2003; 85(3):499-506. [PubMed: 14498785]

Carver CS, Johnson SL. Tendencies toward mania and tendencies toward depression have distinct motivational, affective, and cognitive correlates. Cognitive Therapy and Research. 2009; 33(6): 552-569. [PubMed: 20376291]

Cassidy F, Forest K, Murry E, Carroll BJ. A factor analysis of the signs and symptoms of mania. Archives of General Psychiatry. 1998; 55(1):27-32. [PubMed: 9435757]

Clark L, Sarna A, Goodwin GM. Impairment of executive function but not memory in first-degree relatives of patients with bipolar I disorder and in euthymic patients with unipolar depression. The American Journal of Psychiatry. 2005; 162(10):1980-1982. [PubMed: 16199852]

Colvin K. Mood disorders and symbolic function: An investigation of object relations and ego development in classical musicians. Dissertation Abstracts International: Section B: The Sciences and Engineering,. 1995; 55(11-B):5062.

Coryell W, Endicott J, Keller M, Andreasen N, Grove W, Hirschfeld RM, et al. Bipolar affective disorder and high achievement: A familial association. The American Journal of Psychiatry. 1989; 146:983-988. (Journal Article). [PubMed: 2750997]

Coyne JC. Self-reported distress: Analog or ersatz depression? Psychological Bulletin. 1994; 116:2945. [PubMed: 8078972]

Csikszentmihalyi, M.; Rathunde, K. The development of the person: An experiential perspective on the ontogenesis of psychological complexity. Damon, W.; Lerner, RM., editors. Hoboken, NJ, US: John Wiley \& Sons Inc.; 1998.

Czeizel, E. Aki költõ akar lenni, pokolra kell annak menni? Magyar költõ-géniuszok testi és lelki betegségei. Budapest: GMR Reklámügynökség; 2001.

Davis MA. Understanding the relationship between mood and creativity: A meta-analysis. Organizational Behavior and Human Decision Processes. 2009; 108(1):25-38.

De Dreu CKW, Baas M, Nijstad BA. Hedonic tone and activation level in the mood-creativity link: Toward a dual pathway to creativity model. Journal of Personality and Social Psychology. 2008; 94(5):739-756. [PubMed: 18444736]

DeMoss K, Milich R, DeMers S. Gender, creativity, depression, and attributional style in adolescents with high academic ability. Journal of Abnormal Child Psychology. 1993; 21(4):455-467. [PubMed: 8408990]

Depue RA, Krauss S, Spoont MR, Arbisi P. General behavior inventory identification of unipolar and bipolar affective conditions in a nonclinical university population. Journal of Abnormal Psychology. 1989; 98(2):117-126. [PubMed: 2708652]

DeYoung CG, Quilty LC, Peterson JB. Between facets and domains: 10 aspects of the big five. Journal of Personality and Social Psychology. 2007; 93(5):880-896. [PubMed: 17983306]

Dickstein DP, Nelson EE, McClure EB, Grimley ME, Knopf L, Brotman MA, et al. Cognitive flexibility in phenotypes of pediatric bipolar disorder. [Research Support, N.I.H., Extramural Research Support, N.I.H. Intramural]. Journal of the American Academy of Child and Adolescent Psychiatry. 2007; 46(3):341-355. [PubMed: 17314720]

Duncker K. On problem solving. Psychological Monographs. 1945; 58(5)

Eckblad M, Chapman LJ. Development and validation of a scale for hypomanic personality. Journal of Abnormal Psychology. 1986; 95(3):214-222. [PubMed: 3745642]

Eisner LR, Johnson SL, Carver CS. Cognitive responses to failure and success relate uniquely to bipolar depression versus mania. Journal of Abnormal Psychology. 2008; 117(1):154-163. [PubMed: 18266493]

England, P.; Kilbourne, B. Occupational measures from the dictionary of occupational titles for 1980 census detailed occupations. Ann Arbor, MI: Inter-university Consortium for Political and Social Research; 1988. 
Eysenck HJ. Creativity and personality: Suggestions for a theory. Psychological Inquiry. 1993; 4(3): 147-178.

Feist GJ. A meta-analysis of personality in scientific and artistic creativity. Personality and Social Psychology Review. 1998; 2(4):290-309. [PubMed: 15647135]

Figueroa CG. Virginia Woolf as an example of a mental disorder and artistic creativity. Revistamedica de Chile. 2005; 133(11):1381-1388.

Fodor EM. Subclinical inclination toward manic-depression and creative performance on the remote associates test. Personality and Individual Differences. 1999; 27:1273-1283.

Fodor EM, Greenier KD. The power motive, self-affect, and creativity. Journal of Research in Personality. 1995; 29(2):242-252.

Folley BS, Park S. Verbal creativity and schizotypal personality in relation to prefrontal hemispheric laterality: A behavioral and near-infrared optical imaging study. Schizophrenia Research. 2005; 80(2-3):271-282. [PubMed: 16125369]

Frantom C, Sherman MF. At what price art? Affective instability within a visual art. Creativity Research Journal. 1999; 12:15-23.

Fredrickson BL. What good are positive emotions? Review of General Psychology. 1998; 2(3):300_ 319. [PubMed: 21850154]

Fredrickson BL. The role of positive emotions in positive psychology: The broadenand- build theory of positive emotions. American Psychologist. 2001; 56(3):218-226. [PubMed: 11315248]

Fredrickson BL, Branigan C. Positive emotions broaden the scope of attention and thought-action repertoires. Cognition and Emotion. 2005; 19(3):313-332. [PubMed: 21852891]

Fredrickson BL, Cohn MA, Coffey KA, Pek J, Finkel SM. Open hearts build lives: Positive emotions, induced through loving-kindness meditation, build consequential personal resources. Journal of Personality and Social Psychology. 2008; 95(5):1045-1062. [PubMed: 18954193]

Furnham A, Batey M, Anand K, Manfield J. Personality, hypomania, intelligence and creativity. Personality and Individual Differences. 2008; 44(5):1060-1069.

Ghaemi SN, Bauer M, Cassidy F, Malhi GS, Mitchell P, Phelps J, et al. Diagnostic guidelines for bipolar disorder: A summary of the International Society for Bipolar Disorders Diagnostic Guidelines Task Force Report. Bipolar Disorders. 2008; 10(1 Pt 2):117-128. [PubMed: 18199230]

Goodwin, FK.; Jamison, KR. Manic-depressive illness: Bipolar disorders and recurrent depression. New York: Oxford University Press; 2007.

Gorrindo T, Blair RJ, Budhani S, Dickstein DP, Pine DS, Leibenluft E. Deficits on a probabilistic response-reversal task in patients with pediatric bipolar disorder. The American Journal of Psychiatry. 2005; 162:1975-1977. (Journal Article). [PubMed: 16199850]

Gough HG. A creative personality scale for the adjective check list. Journal of Personality and Social Psychology. 1979; 37(8):1398-1405.

Gruber J, Johnson SL. Positive emotional traits and ambitious goals among people at risk for bipolar disorder. International Journal of Cognitive Therapy. 2009; 2:176-187. (Journal Article). [PubMed: 20360995]

Gruber J, Johnson SL, Oveis C, Keltner D. Risk for mania and positive emotional responding: Too much of a good thing? Emotion. 2008; 8(1):23-33. [PubMed: 18266513]

Guilford, JP. The nature of human intelligence. New York: McGraw-Hill; 1967.

Harmon-Jones E, Abramson LY, Nusslock R, Sigelman JD, Urosevic S, Turonie LD, et al. Effect of bipolar disorder on left frontal cortical responses to goals differing in valence and task difficulty. Biological Psychiatry. 2008; 63(7):693-698. [PubMed: 17919457]

Hayden EP, Bodkins M, Brenner C, Shekhar A, Nurnberger JI Jr, O'Donnell BF, et al. A multimethod investigation of the behavioral activation system in bipolar disorder. Journal of Abnormal Psychology. 2008; 117(1):164-170. [PubMed: 18266494]

Hocevar, D.; Bachelor, P. A taxonomy and critique of measurements used in the study of creativity. New York, NY, US: Plenum Press; 1989.

Isen AM, Daubman KA. The influence of affect on categorization. Journal of Personality and Social Psychology. 1984; 47(6):1206-1217. 
Isen AM, Daubman KA, Nowicki GP. Positive affect facilitates creative problem solving. Journal of Personality and Social Psychology. 1987; 52(6):1122-1131. [PubMed: 3598858]

Isen AM, Johnson MM, Mertz E, Robinson GF. The influence of positive affect on the unusualness of word associations. Journal of Personality and Social Psychology. 1985; 48(6):1413-1426. [PubMed: 4020605]

Jamison KR. Mood disorders and patterns of creativity in British writers and artists. Psychiatry. 1989; 52(2):125-134. [PubMed: 2734415]

Jamison, KR. Touched with fire: Manic-depressive illness and the artistic temperament. New York: Simon and Schuster; 1993.

Jamison KR, Gerner RH, Hammen C, Padesky C. Clouds and silver linings: Positive experiences associatedwith primary affective disorders. The American Journal of Psychiatry. 1980; 137(2): 198-202. [PubMed: 7352574]

Johnson SL. Mania and dysregulation in goal pursuit: A review. Clinical Psychology Review. 2005; 25:241-262. [PubMed: 15642648]

Johnson SL, Carver CS. Extreme goal setting and vulnerability to mania among undiagnosed young adults. Cognitive Therapy and Research. 2006; 30:377-395. [PubMed: 20198117]

Johnson SL, Eisner LR, Carver CS. Elevated expectancies among persons diagnosed with bipolar disorder. British Journal of Clinical Psychology. 2009; 48(2):217-222. [PubMed: 19254445]

Johnson SL, Carver CS, Siegel RS. Social dominance among persons at risk for bipolar disorders: Motivation for dominance, perceptions of rank, and socially dominant behaviors. 2011 Unpublished manuscript.

Juda A. The relationship between highest mental capacity and psychic abnormalities. American Psychiatry. 1949; 106:296-307.

Judd LL, Akiskal HS, Schettler PJ, Coryell W, Maser J, Rice JA, et al. The comparative clinical phenotype and long term longitudinal episode course of bipolar I and II: A clinical spectrum or distinct disorders? Journal of Affective Disorders. 2003; 73(1-2):19-32. [PubMed: 12507734]

Judd LL, Akiskal HS, Schettler PJ, Endicott J, Leon AC, Solomon D, et al. Psychosocial disability in the course of bipolar I and II disorders: A prospective, comparative, longitudinal study. Archives of General Psychiatry. 2005; 62:1322-1330. [PubMed: 16330720]

Judd LL, Akiskal HS, Schettler PJ, Endicott J, Maser J, Solomon DA, et al. The long-term natural history of the weekly symptomatic status of bipolar I disorder. Archives of General Psychiatry. 2002; 59(6):530-537. [PubMed: 12044195]

Judd LL, Hubbard B, Janowsky DS, Huey LY, Takahashi KI. The effect of lithium carbonate on the cognitive functions of normal subjects. Archives of General Psychiatry. 1977; 34:355-357. [PubMed: 320957]

Kahana, SY. A 3-year follow-up of youth diagnosed with subsyndromal bipolar disorder: Symptom stability and predictors of recovery and relapse. Cleveland: Ph. D., Case Western Reserve University; 2006.

Kahn BE, Isen AM. The influence of positive affect on variety seeking among safe, enjoyable products. Journal of Consumer Research. 1993; 20(2):257-270.

Karam EG, Salamoun M, Yeretzian JS, Mneimneh Z, Karam AN, Fayyad J, et al. The role of anxious and hyperthymic temperaments in mental disorders: A national epidemiologic study. World Psychiatry. 2010; 9(2):103-110. [PubMed: 20671899]

Khatena, J.; Torrance, EP. Manual for Khatena-Torrance creative perception inventory. Chicago, IL: Stoelting; 1976.

King R, Curtis D, Knoblich G. Complexity preference in substance abusers and controls: Relationships to diagnosis and personality variables. Perceptual and Motor Skills. 1991; 72(1):35-39. [PubMed: 2038532]

Klein DN, Kotov R, Bufferd SJ. Personality and depression: Explanatory models and review of the evidence. Annual Review of Clinical Psychology. 2011; 7:269-295.

Kocsis JH, Shaw ED, Stokes PE, Wilner P, Elliot AS, Sikes C, et al. Neuropsychologic effects of lithium discontinuation. Journal of Clinical Psychopharmacology. 1993; 13(4):269-275. 
Kwapil TR, Miller MB, Zinser MC, Chapman LJ, Chapman J, Eckblad M. A longitudinal study of high scorers on the hypomanic personality scale. Journal of Abnormal Psychology. 2000; 109(2): 222-226. [PubMed: 10895560]

Levine J, Schild K, Kimhi R, Schreiber G. Word associative production in affective versus schizophrenic psychoses. Psychopathology. 1996; 29(1):7-13. [PubMed: 8711078]

Lewinsohn PM, Klein DN, Seeley JR. Bipolar disorder during adolescence and young adulthood in a community sample. Bipolar Disorders. 2000; 2:281-293. [PubMed: 11249806]

Locke EA, Latham GP. Building a practically useful theory of goal setting and task motivation: A 35year odyssey. American Psychologist. 2002; 57(9):705-717. [PubMed: 12237980]

Lovejoy MC, Steuerwald BL. Subsyndromal unipolar and bipolar disorders: Comparisons on positive and negative affect. Journal of Abnorma Psychology. 1995; 104(2):381-384.

Ludwig AM. Creative achievement and psychopathology: Comparison among professions. American Journal of Psychotherapy. 1992; 46(3):330-356. [PubMed: 1530096]

Ludwig AM. Mental illness and creative activity in female writers. The American Journal of Psychiatry. 1994; 151(11):1650-1656. [PubMed: 7943456]

Lumry AE, Gottesman II, Tuason VB. MMPI state dependency during the course of bipolar psychosis. Psychiatry Research. 1982; 7(1):59-67. [PubMed: 6957901]

$\mathrm{Ma} \mathrm{H}$. The effect size of variables associated with creativity: A meta-analysis. Creativity Research Journal. 2009; 21(1):30-42.

MacCabe JH, Lambe MP, Cnattingius S, Sham PC, David AS, Reichenberg A, et al. Excellent school performance at age 16 and risk of adult bipolar disorder: National Cohort Study. The British Journal of Psychiatry: The Journal of Mental Science. 2010; 196(2):109-115. [PubMed: 20118454]

McCrae, RR.; Costa, PT. Conceptions and correlates of openness to experience. In: Hogan, R.; Johnson, J.; Briggs, S., editors. Handbook of Personality psychology. San Diego, CA: Academic Press; 1997. p. 825-847.

McCrae RR, Ingraham LJ. Creativity, divergent thinking, and openness to experience. Journal of Personality and Social Psychology. 1987; 52(6):1258-1265.

Mednick S. The associative basis of the creative process. Psychological Review. 1962; 69(3):220-232. [PubMed: 14472013]

Mednick, SA.; Mednick, MP. Examiner's manual: Remote associates test. Boston, MA: Houghton Mifflin; 1967.

Merikangas KR, Pato M. The epidemiology of bipolar disorder in adults and children: Magnitude, correlates and future directions. Clinical Psychology: Science and Practice. 2009; 16(2):121-133.

Meyer TD. The hypomanic personality scale, the Big Five, and their relationship to depression and mania. Personality and Individual Differences. 2002; 32:649-660.

Meyer B, Beevers CG, Johnson SL. Goal appraisals and vulnerability to bipolar disorder: A personal projects analysis. Cognitive Therapy and Research. 2004; 28(2):173-182.

Meyer T, Krumm-Merabet C. Academic performance and expectations for the future of people putatively at risk for bipolar disorders. Personality and Individual Differences. 2003; 35:785796.

Myin-Germeys I, van Os J, Schwartz JE, Stone AA, Delespaul PA. Emotional reactivity to daily life stress in psychosis. Archives of General Psychiatry. 2001; 58(12):1137-1144. [PubMed: 11735842]

Oedegaard KJ, Syrstad VEG, Morken G, Akiskal HS, Fasmer OB. A study of age at onset and affective temperaments in a Norwegian sample of patients with mood disorders. Journal of Affective Disorders. 2009; 118(1-3):229-233. [PubMed: 19243836]

Peluso MAM, Hatch JP, Glahn DC, Monkul ES, Sanches M, Najt P, et al. Trait impulsivity in patients with mood disorders. Journal of Affective Disorders. 2007; 100(1-3):227-231. [PubMed: 17097740]

Polatin P, Fieve RR. Patient rejection of lithium carbonate prophylaxis. Journal of the American Medical Association. 1971; 218(6):864-866. [PubMed: 5170924] 
Post RD. MMPI predictors of mania among psychiatric inpatients. Journal of Personality Assessment. 1986; 50(2):248-256. [PubMed: 3761127]

Prisciandaro JJ, Roberts JE. Evidence for the continuous latent structure of mania in the epidemiologic catchment area from multiple latent structure and construct validation methodologies. Psychological Medicine. 2011; 41(3):575-588. [PubMed: 20507671]

Ramey CH, Weisberg RW. The "poetical activity" of Emily Dickinson: A further test of the hypothesis that affective disorders foster creativity. Creativity Research Journal. 2004; 16(2-3): 173-185.

Rathunde K. Broadening and narrowing in the creative process: A commentary on Fredrickson's "broaden-and-build" model. Prevention and Treatment. 2000; 3(6):1-6.

Rawlings D, Georgiou G. Relating the components of figure preference to the components of hypomania. Creativity Research Journal. 2004; 16(1):49-57.

Rende B. The contribution of cognitive resources to performance on verbal fluency tasks. US: ProQuest Information \& Learning 60. 2000

Repp BH. The difficulty of measuring musical quality (and quantity): Commentary on R.W. Weisberg 1994. Genius and madness? A quasi-experimental test of the hypothesis that manic-depression increases creativity (Psychological Science 5, 361-367). Haskins Laburatories Status Report on Speech Research 1994-1995, SR-119/120. 1994:279-281.

Richards R, Kinney DK. Mood swings and creativity. Creativity Research Journal. 1990; 3(3):202217.

Richards R, Kinney DK, Benet M, Merzel AP. Assessing everyday creativity: Characteristics of the lifetime creativity scales and validation with three large samples. Journal of Personality and Social Psychology. 1988; 54(3):476-485.

Richards RL, Kinney DK, Lunde I, Benet M, Merzel A. Creativity in manic-depressives, cyclothymes, their normal relatives, and control subjects. Journal of Abnormal Psychology. 1988; 97:281-288. [PubMed: 3192819]

Roe A. The personality of artists. Educational and Psychological Measurement. 1946; 6:401-408.

Roe A. A psychological sutdy of eminent biologists. Psychological Monographs. 1951; 65:1-68.

Rosch E. Cognitive representations of semantic categories. Journal of Experimental Psychology. General. 1975; 104:192-233.

Rothenberg A. Bipolar illness, creativity, and treatment. Psychiatric Quarterly. 2001; 72(2):131-147. [PubMed: 11433879]

Rowe G, Hirsh JB, Anderson AK, Smith EE. Positive affect increases the breadth of attentional selection. PNAS Proceedings of the National Academy of Sciences of the United States of America. 2007; 104(1):383-388.

Runco MA. Creativity. Annual Review of Psychology. 2004; 55:657-687. (Journal Article).

Santosa CM, Strong CM, Nowakowska C, Wang PW, Rennicke CM, Ketter TA. Enhanced creativity in bipolar disorder patients: A controlled study. Journal of Affective Disorders. 2007; 100(1-3): 31-39. [PubMed: 17126406]

Schmitz TW, De Rosa E, Anderson AK. Opposing influences of affective state valence on visual cortical encoding. The Journal of Neuroscience. 2009; 29(22):7199-7207. [PubMed: 19494142]

Schooler, JW.; Melcher, J. The ineffability of insight. Smith, SM.; Ward, TB.; Finke, RA., editors. Cambridge, MA: The MIT Press; 1995. p. 97-133.

Schou M. Lithium in psychiatric therapy and prophylaxis. Journal of Psychiatry Research. 1968; 6:6795.

Schou M. Artistic productivity and lithium prophylaxis in manic-depressive illness. The British Journal of Psychiatry. 1979; 135(2):97-103. [PubMed: 497639]

Schuldberg D. Creativity and psychopathology: Categories, dimensions, and dynamics. Creativity Research Journal. 2001; 13(1):105-110.

Schuldberg D. Six subclinical spectrum traits in normal creativity. Creativity Research Journal. 2010; 13(1):5-16.

Scott J, Stanton B, Garland A, Ferrier IN. Cognitive vulnerability in patients with bipolar disorder. Psychological Medicine. 2000; 30:467-472. [PubMed: 10824667] 
Shapiro PJ, Weisberg RW. Creativity and bipolar diathesis: Common behavioural and cognitive components. Cognition and Emotion. 1999; 13(6):741-762.

Shaw ED, Mann JJ, Stokes PE, Manevitz AZ. Effects of lithium carbonate on associative productivity and idiosyncrasy in bipolar outpatients. The American Journal of Psychiatry. 1986; 143(9):11661169. [PubMed: 3092681]

Silvia PJ, Kimbrel NA. A dimensional analysis of creativity and mental illness: Do anxiety and depression symptoms predict creative cognition, creative accomplishments, and creative selfconcepts? Psychology of Aesthetics, Creativity, and the Arts. 2010; 4(1):2-10.

Silvia PJ, Nusbaum EC, Berg C, Martin C, O'Connor A. Openness to experience, plasticity, and creativity: Exploring lower-order, high-order, and interactive effects. Journal of Research in Personality. 2009; 43(6):1087-1090.

Simeonova DI, Chang KD, Strong C, Ketter TA. Creativity in familial bipolar disorder. Journal of Psychiatric Research. 2005; 39(6):623-631. [PubMed: 16157163]

Simpson SG, Folstein SE, Meyers DA, McMahon FJ, Brusco DM, DePaulo JR Jr. Bipolar II: The most common bipolar phenotype? The American Journal of Psychiatry. 1993; 150(6):901-903. [PubMed: 8494066]

Soto D, Funes MJ, Guzmán-García A, Warbrick T, Rotshtein P, Humphreys GW. Pleasant music overcomes the loss of awareness in patients with visual neglect. PNAS Proceedings of the National Academy of Sciences of the United States of. America. 2009; 106(14):6011-6016.

Spielberger CD, Parker JB, Becker J. Conformity and achievement in remitted manic-depressive patients. The Journal of Nervous and Mental Disease. 1963; 137:162-172. (Journal Article). [PubMed: 14047823]

Srivastava S, Childers ME, Baek JH, Strong CM, Hill SJ, Warsett KS, et al. Toward interaction of affective and cognitive contributors to creativity in bipolar disorders: A controlled study. Journal of Affective Disorders. 2010; 125(1-3):27-34. [PubMed: 20085848]

Srivastava S, Ketter TA. The link between bipolar disorders and creativity: evidence from personality and temperament studies. Current Psychiatry Reports. 2010; 12(6):522-530. [PubMed: 20936438]

Stern GS, Berrenberg JL. Skill-set, success outcome, and mania as determinants of the illusion of control. Journal of Research in Personality. 1979; 13:206-220. (Journal Article).

Sternberg, RJ. Wisdom, intelligence, creativity, synthesized. New York, New York: Cambridge Univeristy Press; 2003.

Sternberg RJ. The nature of creativity. Creativity Research Journal. 2006; 18(1):87-98.

Stoll AL, Locke CA, Vuckovic A, Mayer PV. Lithium-associated cognitive and functional deficits reduced by a switch to divalproex sodium: A case series. The Journal of Clinical Psychiatry. 1996; 57:356-359. [PubMed: 8752018]

Strakowski SM, Fleck DE, DelBello MP, Adler CM, Shear PK, Kotwal R, et al. Impulsivity across the course of bipolar disorder. Bipolar Disorders. 2010; 12(3):285-297. [PubMed: 20565435]

Strakowski SM, Fleck DE, Delbello MP, Adler CM, Shear PK, McElroy SL, et al. Characterizing impulsivity in mania. Bipolar Disorders. 2009; 11(1):41-51. [PubMed: 19133965]

Strong CM, Nowakowska C, Santosa CM, Wang PW, Kraemer HC, Ketter TA. Temperamentcreativity relationships in mood disorder patients, healthy controls and highly creative individuals. Journal of Affective Disorders. 2007; 100(1-3):41-48. [PubMed: 17126408]

Swann AC, Anderson JC, Dougherty DM, Moeller FG. Measurement of inter-episode impulsivity in bipolar disorder. Psychiatry Research. 2001; 101(2):195-197. [PubMed: 11286822]

Swann AC, Dougherty DM, Pazzaglia PJ, Pham M, Moeller FG. Impulsivity: A link between bipolar disorder and substance abuse. Bipolar Disorders. 2004; 6(3):204-212. [PubMed: 15117399]

Talarico JM, Bernsten D, Rubin DC. Positive emotions enhance recall of peripheral details. Cognition and Emotion. 2009; 23(2):380-398. [PubMed: 21359127]

Topolinski S, Reber R. Gaining insight Into the "Aha” experience. Current Directions in Psychological Science. 2010; 19(6):402-405.

Torrance, EP. Torrance tests of creative thinking. Bensenville, IL: Scholastic Testing Service; 1990. 
Tremblay CH, Grosskopf S, Yang K. Brainstorm: Occupational choice, bipolar illness and creativity. Economics and Human Biology. 2010; 8(2):233-241. [PubMed: 20138016]

Tsuchiya KJ, Agerbo E, Byrne M, Mortensen PB. Higher socio-economic status of parents may increase risk for bipolar disorder in the offspring. Psychological Medicine. 2004; 34:787-793. [PubMed: 15500299]

Van Meter A, Moreira AL, Youngstrom EA. Meta-analysis of epidemiological studies of pediatric bipolar disorder. Journal of Clinical Psychiatry. 2011; 72(9):1250-1256. [PubMed: 21672501]

Verhaeghen P, Joormann J, Khan R. Why we sing the blues: The relation between self-reflective rumination, mood, and creativity. Emotion. 2005; 5(2):226-232. [PubMed: 15982087]

Wadlinger HA, Isaacowitz DM. Looking happy: The experimental manipulation of a positive visual attention bias. Emotion. 2008; 8(1):121-126. [PubMed: 18266522]

Weisberg RW. Genius and madness? A quasiexperimental test of the hypothesis that manic-depression increases creativity. Psychological Science. 1994; 5:361-367.

Wills GI. Forty lives in the bebop business: Mental health in a group of eminent jazz musicians. The British Journal of Psychiatry: the Journal of mental Science. 2003; 183:255-259. (Journal Article). [PubMed: 12949000]

Wood AM, Tarrier N. Positive clinical psychology: A new vision and strategy for integrated research and practice. Clinical Psychology Review. 2010; 30(7):819-829. [PubMed: 20655136]

Wright K, Lam D, Newsom-Davis I. Induced mood change and dysfunctional attitudes in remitted bipolar I affective disorder. Journal of Abnormal Psychology. 2005; 114(4):689-696. [PubMed: 16351389] 


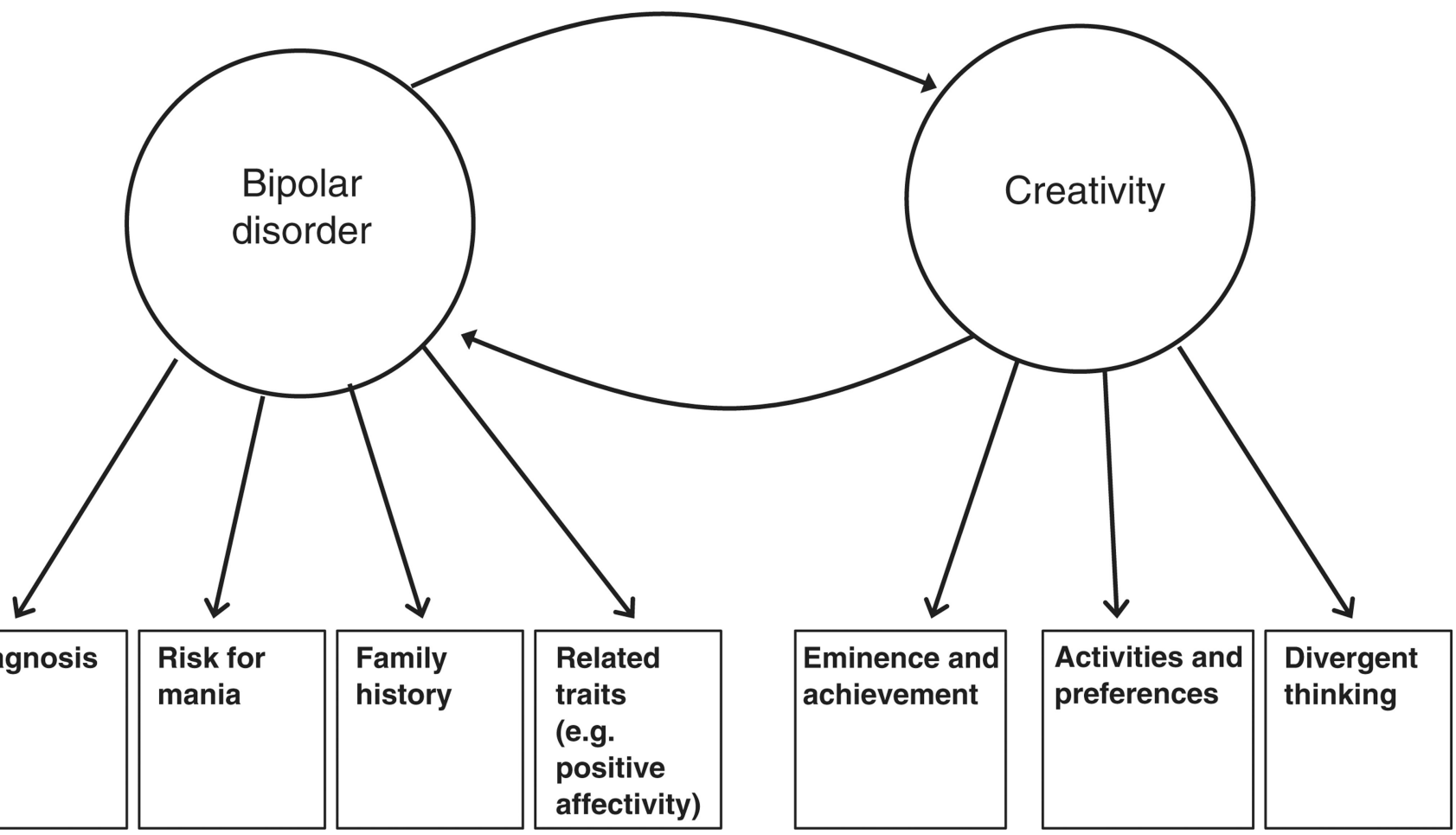

Fig. 1.

This review focuses on several aspects of bipolar disorder and their relationship to multiple measures of creativity. 


\section{Table 1}

Biographical studies of rates of bipolar disorder among famous artists.

\begin{tabular}{lll}
\hline Author (year) & Sample & Rates of mania \\
\hline Ludwig, 1992 & $\begin{array}{l}\text { 1005 persons whose } \\
\text { biographies were reviewed } \\
\text { in the New York Times Book } \\
\text { review between 1960 } \\
\text { and 1990 }\end{array}$ & $\begin{array}{l}\text { 8.2\% had history of mania, } \\
\text { compared to 2.8\% of non-artists. } \\
\text { Mania was most common } \\
\text { among persons who excelled } \\
\text { in theater, architecture, writing, } \\
\text { musical performance and art. }\end{array}$ \\
Wills, 2003 & $\begin{array}{l}\text { 40 famous Jazz Bepop } \\
\text { musicians }\end{array}$ & $\begin{array}{l}28.5 \% \text { had some form of mood } \\
\text { disorder }\end{array}$ \\
Czeizel, 2001 & $\begin{array}{l}\text { Famous Hungarian poets } \\
\text { Jamison, 1989 }\end{array}$ & $\begin{array}{l}\text { 47 British 18th century } \\
\text { bipolar disorder }\end{array}$ \\
writers & $\begin{array}{l}\text { 26\% reported periods of elated } \\
\text { mood, 6.5\% treated for mania }\end{array}$ \\
113 highly creative artists 1949 & $\begin{array}{l}\text { No diagnosable bipolar } \\
\text { disorder, but 22\% of offspring } \\
\text { had bipolar spectrum traits }\end{array}$ \\
\hline
\end{tabular}


Table 2

Studies of self-rated creativity.

\begin{tabular}{|c|c|c|c|}
\hline Author (year) & Sample & $\begin{array}{l}\text { Measure of } \\
\text { Self-Rated } \\
\text { Creativity }\end{array}$ & Findings \\
\hline Furnham et al., 2008 & Students at risk for mania & ACL-CPS & + \\
\hline Schuldberg, 2001 & Students at risk for mania & ACL-CPS & + \\
\hline Shapiro \& Weisberg, 1999 & Students at risk for mania & ACL-CPS & + \\
\hline Frantom \& Sherman, 1999 & $\begin{array}{l}\text { Risk for mania among } \\
\text { graduate students and } \\
\text { faculty studying art }\end{array}$ & $\begin{array}{l}\text { What kind of } \\
\text { person am I }\end{array}$ & No effect \\
\hline $\begin{array}{l}\text { Frantom \& Sherman, 1999, } \\
\text { second analysis }\end{array}$ & Family history of mania & $\begin{array}{l}\text { What kind of } \\
\text { person am I }\end{array}$ & + \\
\hline Santosa et al., 2007 & $\begin{array}{l}\text { People diagnosed with } \\
\text { bipolar disorder }\end{array}$ & ACL-CPS & No effect \\
\hline
\end{tabular}

Note ACL-CPS $=$ Adjective Checklist Creative Personality Scale. 